\title{
EFEKTIVITAS PENERAPAN STRATEGI REACT TERHADAP KEMAMPUAN KONEKSI MATEMATIS DAN SELF-EFFICACY SISWA SMP
}

\author{
Asep Ikin Sugandi ${ }^{1}$, Padillah Akbar ${ }^{2}$ \\ ${ }^{1,2}$ IKIP SILIWANGI, Jl. Terusan Jenderal Sudirman Kebon Rumput Cimahi 40526 \\ asepikinsugandi@gmail.com
}

\begin{abstract}
The purpose of this study is to examine the effectiveness of the REACT Strategy (Relating, Experiencing, Applying, Cooperating, Transferring) on the ability of students' mathematical connections and self-efficacy. The population in this study were all state junior high school students in the city of Cimahi, while the sample was taken from one class from one of the state junior high schools in the city of Cimahi. The instrument in this research was in the form of a test in the form of 5 question items and a non test in the form of a Likert scale with four answer options. The data analysis technique used is the one sample t-test using SPPS version 24 . The results of this research show that the REACT learning strategy is effective for students' mathematical connection skills and self-efficacy.
\end{abstract}

Keywords: Mathematical Connection, self-efficacy, React Strategy

\begin{abstract}
Abstrak
Tujuan dalam penelitian ini adalah menelaah efektivitas Strategi REACT (Relating, Experiencing, Applying, Cooperating, Transferring) terhadap kemampuan koneksi matematis dan self-efficacy siswa. Populasi dalam penelitian ini adalah seluruh siswa SMP Negeri di kota Cimahi, sedakan sampelnya diambil satu kelas dari salah satu SMP Negeri di Kota Cimahi. Instrumen dalam penlitian ini berupa tes dengan bentuk soal uraian sebanyak 5 soal dan non tes berbentuk skla Likert dengan empat option jawaban. Teknik analisis data yang digunakan uji one sample t-test dengan menggunakan SPPS versi 24. Hasil penelitaian ini menunjukakn bahwa strategi pembelajaran REACT efektif terhadap kemampuan koneksi matematis dan self-efficacy siswa.
\end{abstract}

Kata kunci: Koneksi matematis, Self-efficacy, Strategi React

Matematika disebut sebagai pelayan ilmu, yang artinya matematika melayani dan digunakan dalam berbagai bidang pelajaran yang ada di sekolah serta digunakan dalam kehidupan sehari-hari. (Isnaeni, Ansori, Akbar, \& Bernard, 2018; Wiliawanto, Bernard, \& Sugandi, 2019; Akbar, Hamid, Bernard, \& Sugandi, 2018). Kemampuan koneksi matematis adalah suatu kompetensi yang penting untuk dikembangkan siswa. Hal ini sesuai dengan tujuan utama dalam Kurikulum 2013 dan KTSP 2006 (Hendriana, Rohaeti \& Sumarmo, 2017) menyebutkan pembelajaran matematika memiliki tujuan hendaknya siswa menyandang kompetensi diantaranya menguasai ide-ide dalam matematika dan kaitannya serta mengaplikasikannya pada situasi pemecahan masalah secara tepat dan akurat. Disamping itu NCTM 2000 (Hendriana, Rohaeti \& Sumarmo, 2017) menyatakan kemampuan koneksi matematis adalah suatu kemampuan fundamental dalam matematis yang penting dikembangkan pada diri siswa dan dapat didampingkan dengan empat kompetensi lainnya, yaitu: kemampuan memecahkan (problem solving), kemampuan untuk berkomunikasi (communication), bernalar reasoning), dan menggambaran (representation).

Sabandar (2007) menambahkan bahwa pross belajar mengajar matematika di sekolah, disamping bertujuan membuat siswa paham pada konsep yang diajarkan, juga memliki tujuan lainnya berupa kemampuan koneksi dalam matematika yang perlu dicapai siswa ataupun kompetensi serta perilaku spesifik yang didapat setelah siswa mempelajari matematika. berdasarkan urain yang telah 
dipaparkan dapat diambil kesimpulan betapa pentinya penguasaan koneksi matemati dalam pembelajaran matematika. Pada dasarnya matematika adalah $\operatorname{lmu}$ terstruktur, tersusun mulai dari konsep sederhana kearah yang konsep komplek. Penjelasan tersebut melukiskan adanya keterkaitan diantara konsep-konsep matematika. Sumarmo (2014) menjelaskan untuk mengkaji matematika dituntut agar siswa mengerti keterkaian antar konsep matematik dan keterkaitan antar matematik dengan pembelajaran lainnya. Ketika siswa dapat mengkoneksikan antara konsep matematik, maka siswa akan memahami seluruh materi matematika lebih mendalam dan baik. Oleh sebab itu, penguasaan kemampuan koneksi matematik perlu ditanamkan pada diri siswa semenjak dini, karena penguasaan koneksi matematis akan memperluas wawasan dan kemampuan siswa pada matematika. Ini disebabkan segala sesuatu yang dialami dalam kehidupan real ataupun bahan pembelajaran yang dikaji saling berkoneksi. Dari papran yang sudah diuraikan terlihat pentingnya kepemilikan koneksi matematika pada kegitan belajar mengajar matematika.

Namun fakta membuktikan bahwa kompetensi koneksi dalam pembelajaran matematika masih sangat rendah, hal ini sejalan dengan temuan Ruspiani (2000) yang menyimpulkan kemampuan koneksi siswa sangat rendah, adapun nilai reratanya lebih kecil dari 60 dengan skor ideal 100, yaitu untuk koneksi konsp matematik dengan konsep matematik lainnya sekitar 22,2\%, untuk koneksi konsep matematik dengan pelajaran lainnya sekitar $44,9 \%$ dan untuk koneksi konsep matematik dengan persoalan kehidupan sehari-hari sekitar 37,3\%. Ini menyatakan kompetensi koneksi matematis yang didapat siswa sangat rendah jika diukur dari tiga indikator koneksi.

Selain aspek kognitif, pada diri siswa juga terdapat aspek psikologi, salah satunya adalah self-efficacy. Menurut pendapat Bandura (1997) mengatakan self-efficacy adalah keyakinan diri individu terhadap kompetensinya agar dapat mengendalikan dan melakukan serangkaian tindakan dalam mencapai hasil yang ditentukan. Lebih lanjut Schunk (Moma, 2014) menyebutkan bahwa selfefficacy adalah keyakinan diri seseorang tentang apa yang telah dilakukan.

Selanjutnya Bandura (1997) menyatakan self-efficacy dapat ditingkatkan menggunakan empat faktor utama, yaitu : pengalaman yang dilakukan diri sendiri (Mastery Experience), pengalaman yang dilakukan orang lain (Vicarious Experience), Verbal Persuasion serta Physiological and Affective states. Tinggi rendahnya Self-efficacy seseorang bergantung pada pengalaman pribadinya, pembelajaran dengan mengadopsi dari pengalaman seseorang, feedback yang baik atau buruk yang didistribusikan seseorang tentang prestasi individu dan perilaku baik atau buruk yang searah dengan emosi (Setiadi, 2010).

Menurut pengamatan penulis selama pembelajaran berjalan, terdapat siswa yang mempunyai self-efficacy yang masih sangat rendah, ini ditunjukkan dengan sulitnya siswa mengerjakan tugas di depan kelas. Hasil pengamatan tersebut didukung temuan Sukoco dan Mahmudi (2016) yang menyatakan siswa merasa tidak percaya diri bahkan merasa takut jika disuruh guru untuk menjelaskan jawaban yang diperoleh, siswa merasa takut jika jawabanmya salah, dan siswa juga merasa takut jika tidak dapat mengkomunikasikan hasil yang diperolehnya dengan telitu dan akuratr di hadapan teman- 
Efektivitas Penerapan Strategi React Terhadap Kemampuan Koneksi Matematis dan Self-Efficacy Siswa SMP, Asep Ikin Sugandi, Padillah Akbar

temannya.

Dalam usaha meningkatkan koneksi matematis dan self-efficacy siswa diperlukan suatu proseduryang efektif dan efisien untuk melibatkan siswa dalam proses pembelajaran . salah satu strategi pembelajaran yang dapat diambil untuk memenuhi kriteria pembelajaran inovatif adalah strategi Relating, Experiencing, Applying, Cooperating, dan Transferring (REACT)

CORD (1999) menyatakan dalam penerapan strategi REACT siswa ditentukan agar dapat menemukan koneksi penuh arti antara konsep yang abstrak menggunakan penerapan praktis dalam kaitan dengan kehidupan nyata. Siswa mengintegralisasi konsep dengan proses menemukan, menguatkan, dan menghubungkan. Strategi pembelajaran REACT menghendaki adanya kolaborasi dalam tim serta mampu menumbuhkembangkan kinerja siswa. Crawford (2001) menjelaskan Relating adalah prosedur pembelajaran yang dilaksanakan berdasarkan pengalaman sehari-hari siswa kemudian dihubungkan/dikaitkan dengan materi pelajaran agar mendapatkan konsep baru; Experiencing adalah pembelajaran yang menuntut siswa agar belajar melaksanakan aktivitas matematik (doing math) melalui proses eksplorasi, pencarian, dan penemuan; Applying adalah pemebalajaran yang menuntut siswa untuk menggunakan konsep yang sudah didapatnya Cooperating adalah pembelajaran yang menuntut siswa agar belajar bersama, saling berbagi dan merespon serta saling berkomunikasi diantara teman- temannya; sedangkan Transferring adalah pembelajaran yang memacu siswa agar dapat memindahkan pemahaman yang suadah dimilikinya kepada siswa-siswa lain.

Tim Dirjen Dikdasmen (Suhena, 2009,) mengatakan pembelajaran dengan strategi REACT adalah pembelajaran kontekstual, yaitu merupakan pembelajaran yang menunjang guru mengkaitkan materi yang telah dipahami siswa dengan kehidupan real siswa, dan siswa diupayakan agar membuat koneksi antara pemahaman yang dimiliki siswa dengan aplikasi pada kehidupan real sebagai anggota keluarga/ masyarakat. Korelasi materi yang sudah dipelajari dengan kehidupan real akan memberikan efek terhadap tingkat keyakinan diri (kepercayaan diri) siswa agar dapat menggunakan ide matematika dalam dunia real Dengan menggunakan REACT, diharapkan memberikan efektivitas lebih terhadap kompetensi koneksi, problem solving serta self-efficacy siswa dalam rangka mempelajari matematika.

Berdasarkan uraian yang telah dipaparkan di atas, maka tujuan penelitian adalah menelaah efektivitas penggunaan strategi REACT terhadap kemampuan koneksi matematis dan self-efficacy.

\section{METODE PENELITIAN}

Metode penelitian ini adalah eksperimen, karena adanya manipulasi perlakuan berbentuk pemberian strategi REACT. Populasi penelitian ini adalah seluruh siswa SMP Negeri 5 di kota Cimahi, sedangkan sampelnya didapat satu kelas pada SMP Negeri 5 di kota Cimahi. Adapun desain penelitian sebagai berikut:

A $\quad \mathrm{X} \quad \mathrm{O}$

Keterangan : 


\section{A : pemilihan sampel secara acak kelas \\ $\mathrm{X}$ : perlakuan berbentuk pemberian strategi REACT \\ O : Postes/Tes Akhir}

Instrumen tes yang digunakan berbentuk soal urain sebanyak 5 soal yang digunakan mengukur kemampuan konekasi matematis dan non tes berbentuk skala sikap Likert yang memiliki empat opsion yaitu SS (Sangat Setuju), S (Setuju), TS (Tidak Setuju) dan STS (Sangat Tidak setuju) dengan banyaknya pernyataan sebanyak 32 butir dengan 4 buah indikator. Untuk mnegtahui validitas isi dilakukan dengan meminta pertimbangan kepada dosen senior di IKIP Siliwangi, sedangkan validitas kontruks diperoleh berdasarkan hasil uji coba kemudian dihitung validitas dan reliabilitas menggunakan product momen dari Pearson dan Cronbach Alpha. Berdasarkan 1 perhitungan didapat behwa semua instrumen valid dan reliabel baik untuk tes dan nos tes.

Adapun tahapan yang ditempuh pada penelitian ini sebagai berikut : (1) Tahap persiapan meliputi melakukan kajian pustaka tentang kemampuan koneksi matematis, self-efficacy dan strategi REACT, membuat alat evaluasi, membuat bahan untuk pembelajaran, RPP, dan menentukan sampel penelitain, (2) tahap pelaksanaan yang meliputi pemberian strategi REACT dalam pembelajaran selama 8 pertemuan dan selanjutnya adalah tahap evaluasi meliputi pemberian postes dan pengolahan data,

\section{HASIL DAN PEMBAHASAN}

Berdasarkan pengolahan data menggunakan SPSS versi 24 pada kemampuan koneksi matematis dan Self-efficacy siswa disajikan pada Tabel 1 :

\section{Tabel 1.}

Reakapitulasi hasil kemampuan koneksi matematis dan Self-Efficacy

\begin{tabular}{ccc}
\hline & \multicolumn{2}{c}{ Statistik } \\
\cline { 2 - 3 } Aspek yang diukur & $\bar{x}$ & $\mathrm{~s}$ \\
\hline Kemampuan Koneksi Matematis & 16.29 & 2,24 \\
Self Efficacy & 101,82 & 11,30 \\
\hline
\end{tabular}

Sebelum melakukan uji untuk mengetahui efektivitas penerapan strategi REACT terhadap kemampuan koneksi dalam matematika dan self-efficacy, dilakukan terlebih dahulu uji prasyarat yang berupa uji kenormalan data dengan menggunakan uji Kolmogorov-Smirnov, berdasarkan hasil pengolahan data didapat hasil seperti pada Tabel 1 berikut ini

\section{Tabel 2.}

Hasil Uji Normalitas data Kemampuan Koneksi dan Self-Efficacy

\begin{tabular}{cc|c|c}
\hline & \multicolumn{3}{c}{ Kolmogorov-Smirnov $^{\mathrm{a}}$} \\
\cline { 2 - 4 } & Statistic & $\mathrm{df}$ & Sig. \\
\hline Koneksi & 0,140 & 34 & 0200 \\
Self_Efficacy & 0,147 & 34 & 0,060 \\
\hline
\end{tabular}


Pada Tabel 2 didapat nilai sig. untuk kemampuan koneksi matematis sebesar 0,200 maka disimpulkan data kemampuan koneksi matematis berdistribusi normal, adapun untuk self-efficacy didapat nilai signifikasi sebesar 0,060 maka disimpulkan data self-efficacy berdistribusi normal. Selanjutnya diuji tentang keefektifan penerapan strategi REACT terhadap kemampuan koneksi matematis. Hipotesis yang diuji diformulasikan sebagai berikut :

Ho : $\mu \leq 14(70 \% S M I)$

$\mathrm{H}_{1} ; \mu>14(70 \% S M I)$

Kriteria Pengujian Terima Ho, jika nilai sign/2 > 0,05 Dari hasil pengolahan data terhadap hasil kemampuan koneksi matematis siswa, didapat hasil seperti pada Tabel 3 di bawah ini :

\section{Tabel 3}

Hasil Uji-t satu sampel untuk kemampuan koneksi matematis

\begin{tabular}{|c|c|c|c|}
\hline & \multicolumn{3}{|c|}{ Test Value $=14$} \\
\hline & $\mathrm{t}$ & df & Sig. (2-tailed) \\
\hline Koneksi & 5,981 & 33 & 0,000 \\
\hline
\end{tabular}

Dari Tabel 3 didapat nilai sign. Kemampuan koneksi matematis siswa untuk 2 tailed sebesar 0,000, sedangkan untuk 1 tailed (Uyanto, 2009) didapat 0,000/2 =0,000, karena nilai sign. $<0,05$, maka Ho ditolak, sehingga disimpulkan penggunaan strategi REACT efektif terhadap koneksi matematis siswa. Hal ini sejalan dengan temuan Isfayani, Johar, Munzir (2018) menyimpulkan bahwa penerapan model pembelajaran tipe Rotating Trio Exchange (RTE efektif terhadap kemampuan koneksi matematis. Penelitian ini juga sejalan dengan temuan Supriadi (2015) yang menyimpulkan bahwa penggunaaan bahan ajar elektronik interaktif efektif dalam meningkatkan kemampuan koneksi matematis siswa.

Keefektifan strategi REACT yang ditinjau dari hasil pengujian hipotesis menggunakan uji one sample t-test jika dilihat dari kemampuan koneksi matematis sejalan pendapat CORD (1999) yang menyebutkan bahwa:_pembelajaran paling efektif terjadi disaat siswa diminta (dan diajarkan) untuk membentuk koneksi antara pembelajaran (pengalaman) masa lalu dan tindakan dilakukan pada masa mendatang. Kegiatan ini termuat dalam strategi (relating), Siswa diberikan kesempatan untuk menghubungkan pengetahuan dan konsep yang baru pelajari dengan pengetahuan dan konsep yang telah diajarkan atau sudah ada sebelumnya, melalui metode memberikan siswa pertanyaan-pertanyaan dalam usaha membangun ide-ide siswa, fenomena atau objek mengenai materi pembelajaran yang dipresentasikan melalui aktivitas melihat, mengamati, membaca, mendengar, menyimak dan menghubungkan, (experiencing), Siswa mengalami hal-hal yang dipelajarinya secara langsung dengan metode mengumpulkan informasi, melakukan eksperimen, membaca beberapa sumber bacaan yang relevan selain buku teks, memperhatikan kejadian pengalaman, dan (applying) pengaplikasian, Siswa dibimbing untuk memikirkan secara fundamental terhadap ide dan konsep yang dipelajarinya yaitu 
dengan pemikiran berulang, mempelajari, dan mengeksplorasi data yang didapat. Jadi disimpulkan langkah-langkah pembelajaran menggunakan strategi REACT sejalan dengan indikator pada kemampuan koneksi matematis.

Selanjutnya diuji tentang keefektifan penggunaan strategi REACT terhadap self-efficacy. Hipotesis yang diuji diformulasikan sebagai berikut :

Ho : $\mu \leq 90(70 \% S M I)$

$\mathrm{H}_{1} ; \mu>90(70 \% S M I)$

Kriteria pengujian : Terima Ho jika sign $>0,05$

Dari hasil pengujian terhadap hasil Self-Efficacy siswa didapat hasil seperti pada Tabel 4 di bawah ini:

\section{Tabel 4}

Hasil Uji-t satu sampel untuk self-efficacy

\begin{tabular}{|c|c|c|c|}
\hline & \multicolumn{3}{|c|}{ Test Value $=90$} \\
\hline & $\mathrm{t}$ & $\mathrm{df}$ & Sig. (2-tailed) \\
\hline Self- Efficacy & 6,102 & 33 & 0,000 \\
\hline
\end{tabular}

Pada Tabel 4 didapat bahwa nilai sign. Self-efficacy siswa pada 2 tailed sebesar 0,000, sedangkan untuk 1 tailed (Uyanto, 2009) didapat 0,000/2 =0,000, karena sign. $<0,05$ mengakibatkan Ho ditolak, Dari uraian tersebut dapat disimpulkan Penerapan strategi REACT efektif terhadap self-efficacy siswa. Hal ini sesui temuan Moma (2014) yang menyatakan bahwa penerapan pendekatan generatif lebih efektif terhadap Self-efficacy siswa. Penelitian ini juga sejalan dengan penelitian Hardiyanto , Rusgianto \& Santoso (2018) yang menyatakan bahwa pendekatan PBL setting TTW maupun PBL setting TPS Efektif efektif terhadap sel-efficacy siswa. Disamping itu hasil penelitian ini sejalan dengan Isfayani, Johar, Munzir (2018) yang menyimpulkan penerapan model pembelajaran tipe Rotating Trio Exchange (RTE) efektif terhadap self-efficacy siswa. Disamping itu penelitian ini sejalan dengan penelitian Fitri (2017) yang menyatakan penggunaan pendekatan ATI efektif terhadap self-efficacy siswap

Keefektifan strategi REACT yang ditinjau dari analisis deskriptif maupun pengujian hipotesis dengan uji one samplet-test jika ditinjau dari Self-efficacy siswa di atas disimpulkan langkah-langkah dalam strategi REACT searh dengan indikator self-efficacy, misalnya pada tahap relating, Siswa diberikan kesempatan agar dapat menghubungkan pemahaman konsepkonsep baru yang dipelajari siswa dengan pemahaman dan konep-konsep yang sudah diterima atau sudah ada sebelumnya, dengan metode memberikan siswa pertanyaan-pertanyaan agar dapat mngembangkan ide-ide siswa, fenomena atau objek mengenai materi pembelajaran disampaikan dengan kegiatan melihat, mengamati, membaca, mendengar, dan menyimak, dengan demikian ini adalah unsur utama dalam membina sikap percaya diri dengan berkata, "saya mampu mempelajari ini". Dengan demikian kegiatan relating memiliki kaitan dengan indikator self-efficacy yaitu pengalaman pribadi sesorang (mastery experience), kemudian tahap applying (menerapkan), Siswa dibimbing untuk 
memikirkan secara fundamental pada ide yang dipelajarinya yaitu dengan pemikiran berulang, mempelajari, dan mengeksplorasi data/informasi yang didapat, dengan demikian kegiatan applying memiliki kaitan dengan indikator self -efficacy berupa pengalaman pribadi orang lain (vicarious experience). Tahap selanjutnya adalah tahap Cooperating (kerjasama), Siswa ditutntut agar bekerjasama dalam keadaa saling bertukar pikiran, melakukan tanya jawab, melakukan komunikasi yang interaktif antar sesama siswa, dengan guru, dan narasumber, dalam usaha memecahkan masalah dan menyelesaikan tugas secara bersama, dengan demikian kegiatan Cooperating memiliki kaitan dengan indikator self-efficacy yaitu verbal persuasion dan tahap terakhir yaitu tahap Transferring (mentranfer), Siswa diarahkan agar dapat mengkaju dan mengupayan untuk melakukan kegiatan memecahkan masalah dalam keseharian di wilayah dengan mengaplikasikan ilmu yang didapatnya, dengan demikian kegiatan Transferring memiliki kaitan dengan indikator self-efficacy yaitu keadaan phisiologi dan afektif (Physiological and Affective states). Jadi disimpulkan langkah-langkah pembelajaran strategi REACT berkaitan dengan indikator yang terdapat pada self-efficacy.

\section{KESIMPULAN}

Berdasarkan penelitian dan pengujian hipotesis dilakukan maka dapat disimpulkan bahwa Staretgi REACT efektif terhadap koneksi matematis dan self-efficacy siswa.

\section{DAFTAR PUSTAKA}

Akbar, P., Hamid, A., Bernard, M., \& Sugandi, A. I. (2018). Analisis kemampuan pemecahan masalah dan disposisi matematik siswa kelas xi sma putra juang dalam materi peluang. Jurnal Cendekia: Jurnal Pendidikan Matematika, 2(1), 144-153.

Bandura, A. (1997). Self-efficacy: The exercise of control. Macmillan.

Isnaeni, S., Ansori, A., Akbar, P., \& Bernard, M. (2018). MATERI PERSAMAAN DAN PERTIDAKSAMAAN LINEAR SATU. 01(02), 309-316.

Cord. (1999). Teaching mathematics contextually. Texas : CORD Communications, Inc. diakses http://www.cord.org/uploadfiles/Teaching_Math_Contextually.pdf pada tanggal 5 Januari 2013.

Crawford, L.M. (2001). Teaching Contextually: Research, Rationale and Techniques for Improving Student Motivation and Achievement in Mathematics and Science. CORD. Texas: CCI Publishing, Inc.

Fitri, I. (2017). Self-efficacy terhadap matematika melalui pendekatan aptitude treatment interaction. Jurnal Review Pembelajaran Matematika (JRPM) 2017, 2(2), 167-175.

Hardiyanto, H., Rusgianto \& Santoso,H. (2018). Efektivitas PBL setting TTW dan TPS ditinjau dari prestasi belajar, berpikir kritis dan self-efficacy siswa. Jurnal Riset Pendidikan Matematika 5 (1), 2018, 116-126. Yogyakarta : Universitas Negeri Yogyakarta.

Hendriana,H., Rohaeti, E.E \& Sumarmo, U (2017). Hard Skills dan Soft Skills Matematik Siswa. Bandung : Refika Aditama.

Hendriana,H. \& Sumarmo,U. (2014). Penilaian Pembelajaran Matematika. Bandung: Refika Aditama Isfayani, E., Johar, R. \& Munzir (2018). Peningkatan Kemampuan Koneksi Matematis dan Self- Efficacy Siswa melalui Model Pembelajaran Kooperatif Tipe Rotating Trio Exchange (RTE). Jurnal Elemen 4(1). 80 - 92

Moma, L. (2014). Peningkatan Kemampuan Berpiir Kreatif Matematis, Self Eficacy dan Soft Skills Siswa SMP melalui Pembelajaran Generatif. Unpublished Disertasi. UPI Bandung.

Moma,L. (2014). Peningkatan Self-Efficacy Matematis Siswa SMP melalui Pembelajaran Generatif. Jurnal Cakrawala Pendidikan, Oktober 2014, Th. XXXIII, No. 3

Ruspiani (2000). Kemampuan Siswa dalam Melakukan Koneksi Matematika. Unpublished Thesis. UPI 
Bandung.

Sabandar, J. (2007). . Berfikir Reflektif. Makalah Pembicara Utama Seminar Nasional matematika. Bandung: FPMIPA UPI.

Setiadi, R. (2010). Self-ffficacy In Indonesian Literacy Teaching Context: A Theoretical and Empirical Perspective. Bandung: Rizqi Press.

Suhena, E. (2009). Pengaruh strategi REACT dalam pembelajaran matematika terhadap peningkatan kemampuan pemahaman, penalaran dan komunikasi matematis siswa. Unpublished Disertasi. UPI Bandung.

Sukoco, H. \& Mahmudi, A. (2016). Pengaruh Pendekatan Brain-Based Learning terhadap Kemampuan Komunikasi Matematis dan Self-Efficacy Siswa SMA. Jurnal Phytagoras, 11 (1). 11-24. Yogyakarta : Universitas Negeri Yogyakarta

Sumarmo, U. (2014). Pengembangan hard skill dan soft skill matematik bagi guru dan siswa untuk mendukung implementasi kurikulum 2013. In Prosiding Seminar Nasional Pendidikan Matematika Program Pasca Sarjana (pp. 4-15).

Supriadi, N. (2015). Mengembangkan Kemampuan Koneksi Matematis Melalui Buku Ajar Elektronik Interaktif (BAEI) yang Terintegrasi Nilai-Nilai Keislaman. Al-Jabar: Jurnal Pendidikan Matematika, 6(1), 63-74.

Uyanto, S. S. (2009). Pedoman Analisis Data dengan SPSS. Yogyakarta: Graha Ilmu.

Wiliawanto, W., Bernard, M., \& Sugandi, A. I. (2019). PENERAPAN STRATEGI PEMBELAJARAN AKTIF QUESTION STUDENT HAVE UNTUK MENINGKATKAN KEMAMPUAN. 3(1), $136-145$. 